\title{
Vaccination practices among physicians and their children
}

\author{
Michael Martin', Vahe Badalyan ${ }^{2}$ \\ ${ }^{1}$ Department of Pediatrics, Inova Fairfax Hospital for Children, Falls Church, USA \\ ${ }^{2}$ Department of Gastroenterology, Children's National Medical Center, Washington DC, USA \\ Email: michael.martin.md@gmail.com
}

Received 1 May 2012; revised 3 July 2012; accepted 30 July 2012

\begin{abstract}
The purpose of this study was to identify vaccination patterns of both general pediatricians and subspecialists with regards to their own children and projected progeny. A 14 question survey was sent randomly to 1000 members of the Academy of Pediatrics in 2009. Two categories of questions included 1) how physicians with children vaccinated them in the past, and 2) how all respondents would vaccinate a child in 2009. A comparison was made between the answers of general and specialty pediatricians. 582 valid questionnaires were received (58.2\% response rate) of which 431 were general pediatricians and 151 subspecialists. No statistical difference was found between general and specialty pediatricians on how they vaccinated their children up until 2009 (95\% vs $93 \%)$. When asked about vaccinating a future child, a significant proportion of respondents would deviate from CDC guidelines, specialists more than general pediatricians (21\% vs $9 \%$ ). Generalists were more likely to give a future child Hepatitis A (OR: 3.6; 95\% CI 1.3 - 10.4), Rotavirus (OR: 2.2; 95\% CI 1.1 - 4.4), Meningococcal (OR: 9.9; 95\% CI 3.3 - 29.9), and influenza (OR: 5.4; 95\% CI 1.1 - 26.7) vaccines. Specialists were more likely to postpone MMR vaccinetion (OR: 4.4 95\% CI 2.3 - 8.6). Safety was listed by both groups as the most common reason for altering the recommended immunization schedule. Until 2009, general pediatricians and pediatric specialists have largely adhered to ACIP recommendations, but due to vaccine safety and other concerns, both groups, albeit a higher percentage of specialists, reported greater numbers willing to diverge from these recommendations.
\end{abstract}

Keywords: Vaccination; Vaccine Adverse Events; Vaccine Schedule; Pediatricians; Preventable Diseases

\section{INTRODUCTION}

While parents seek information from many sources, phy- sicians remain the most commonly relied on resource of information regarding immunizations [1]. Health care providers influence the rates of immunization by answering parents' questions, addressing misinformation, and ultimately building trust [2-4]. Parents who change their mind from delaying or refusing vaccines for their child most often credit the child's health care provider for this change [5]. This places the pediatrician in a unique position to influence vaccination patterns in the United States.

How pediatricians choose to vaccinate their own children may provide the closest surrogate for their actual beliefs on both the necessity and benefits of immunization and ultimately how they counsel families. Little is documented, however, on how pediatricians vaccinate their children overall [6]. One study in 2005 examined how $93 \%$ of Swiss physicians followed immunization recommendations in that country, but no duplicate study has been performed in the United States to date [7]. A number of prior studies have examined reported acceptance of new vaccines including rotavirus, but not their acceptance of the overall vaccine schedule of the Advisory Committee on Immunization Practices (ACIP) [8-11]. Gust and colleagues in 2008 surveyed largely family practitioners and a smaller number of pediatricians and found $11 \%$ do not recommend to parents that children receive all available vaccines [12]. Barriers to acceptance have included safety, cost, reimbursement, parental acceptance, as well as a perceived lack of need for a vaccine [8-11]. It is important to first identify physicians' beliefs on vaccines in order to improve the counseling they give to families.

Our study was designed to compare how those physicians involved the most with vaccination, namely general pediatricians, compared to pediatric subspecialists, who were less familiar with both vaccine preventable illnesses and the vaccines themselves, in vaccinating their own children as well as future progeny. It was surmised that those persons most familiar with vaccines would be more likely to fully vaccinate their own children. We also examined which vaccines were most often not given or would not be given to future children. 


\section{PATIENTS AND METHODS}

1000 web based questionnaires (Figure 1) were sent to a randomized list of members of the Academy of Pediatrics (AAP). An estimated $80 \%$ of board certified pediatricians are members of the AAP. Included in responses were general pediatricians and pediatric subspecialists currently in the United States. The list of participants was generated from the AAP member directory and every 20th name selected alphabetically at random to participate. If the randomized name did not have a working email or mailing address, the next name in the list was used. This occurred in 11 cases. 223 of those emailed responded to the initial email and 55 responded to the 2 nd email sent out 3 weeks later. The 722 non responders were sent a questionnaire by mail 3 weeks following the 2 nd email request with a $\$ 2$ incentive enclosed in the envelope as well as a stamped envelope for return of the survey. A total of 657 surveys were completed in all. All responses were anonymous.

1. You are a: $\quad \square \quad$ Male $\quad \square \quad$ Female

2. In which state do you primarily practice?

3. Which best describes you? $\square$ General Pediatrician $\quad \square$ Pediatric Subspecialist $\quad \square$ Family Medicine Physician $\quad \square$ Other:

4. When did you complete medical school?

$\begin{array}{llllll}\square \text { After } 2004 & \square \text { 2000-2003 } \square \text { 1990-1999 } \quad \square \text { 1980-1989 } & \square 1970-1979 & \square 1960-1969 & \square \text { Before } 1960\end{array}$

5. You work: (check all that apply)

$\square$ in private practice $\quad \square$ in community clinic $\quad \square$ at a hospital $\quad \square$ in public administration $\quad \square$ for the government

$\square$ in school of medicine $\square$ in the pharmaceutical industry $\quad \square$ other professional area

6. Do you have children? $\square$ Yes $\square$ No (if no, go to question 12)

7. How many children do you have? $\square 1 \quad \square 2 \quad \square 3 \quad \square 4 \quad \square 5$ or more

8. What ages are your child(ren)? (check all that apply) $\square<2$ years old $\quad \square 2-4$ years old $\quad \square 5-10$ years old $\quad \square \geq 11$ years old

9. Did you follow the up-to-date recommended vaccination schedule annually published by the Advisory Committee for Immunization Practices (ACIP) for all of your children as it was written at the time they were vaccinated?

$\square$ Yes (if yes go to question 12) $\quad \square$ No $\quad \square$ I did not know or refer to the guidelines

10. If you did not elect to follow the vaccination schedule or followed an alternative schedule, which vaccines did you elect to postpone or not give? If a vaccine was not available when your child was vaccinated, do not check

it. (check all that apply)

$\begin{array}{lllll}\text { DTaP } & \square \text { Hib }\end{array}$ Prevnar $\quad \square$ IPV $\square$ Rotavirus $\quad \square$ Hep A $\quad \square$ Hep B $\quad \square$ MMR

$\square$ Varicella $\square$ Meningococcal (Menactra) $\quad \square$ Influenza

11. If you elected to not give a vaccine, or to postpone it, which reasons best describe why. (check all that apply)

$\square$ Medical contraindication

$\square$ Too many vaccines given at once

$\square$ Safety concern

$\square$ Vaccine protects against illness that does not present a risk to your child

$\square$ Do not believe in efficacy of vaccine

$\square$ Other (Please explain):

12. If you were a "new parent" in 2009-2010, at what age would you give the first dose of MMR to your own children?

$\begin{array}{llcc}\square<18 \text { months old } & \square 18 \text { months }-2 \text { years old } & \square-5 \text { years old } & \square 6-10 \text { years old } \\ \square>15 \text { years old } & \square \text { would not vaccinate } & & \end{array}$

13. If you were a "new parent" in 2009-2010, which vaccines would you NOT give to your own children? (check all that apply)

$\square$ None - I would give all of them $\quad \square$ DtaP $\quad \square$ Hib $\quad \square$ Prevnar $\quad \square$ IPV $\quad \square$ Rotavirus $\quad \square$ Hepatitis A

$\square$ Hepatitis B $\quad \square$ MMR $\quad \square$ Varicella $\square$ Menactra $\square$ Influenza $\square$ Other (please specify)

14. If were a new parent in 2009-2010 and would not give a vaccine, which reasons best describe why. (check all that apply)

$\square$ Medical contraindication $\quad \square$ Too many vaccines given at once $\quad \square$ Safety concern

$\square$ Vaccine protects against illness that does not present a risk to the individual $\quad \square$ Do not believe in efficacy of vaccine

$\square$ Other (please explain)

Figure 1. Survey sent to physicians. 
The 14 question survey was presented on 6 separate pages as a web survey or a single page as a mailed survey. Questions were divided into 3 distinct sections: 1) gathering demographic information; 2) parent physicians were asked how they vaccinated their own children and if not following recommended schedules for which vaccines and why; and 3) all participants were asked what vaccines they would or would not give to a hypothetical new child. In addition to set responses for skipping or not giving a vaccine, open fields were included to allow for participants to provide answers not included in the options given. Web surveys were entered by participants into Survey Monkey and mailed surveys manually entered into this same program and exported to Microsoft Excel.

Using standard descriptive statistics, demographic characteristics of responding participants is shown in Table 1. Comparisons of baseline demographics and immunization measures were performed by using chi-square tests where appropriate. Univariate statistical analyses were performed for each variable to determine its relationship to the main independent variable, being a general pediatrician or subspecialist. Logistic-regression analysis was used to calculate the adjusted odds rations
(OR) and 95\% confidence interval (CI), controlling for any statistically significant demographic variables that might act as a confounder. Differences were considered significant at $\mathrm{P}<0.05$ and when the $95 \% \mathrm{CI}$ did not include 1.0. SPSS statistical software version 18 (SPSS, Inc., Chicago, IL) was used for the statistical analysis.

\section{RESULTS}

Of the 1000 surveys sent, a total of 582 were utilized in our analysis. 75 participants did not fit the categorization as a pediatric specialist or general pediatrician and were excluded from analysis. These included 5 family physicians, 33 residents, and 37 persons designating themselves as "other" who could not be categorized. Of those surveys analyzed, 431 were completed by general pediatricians and 151 completed by pediatric subspecialists. Subspecialists included a wide representation including pediatric cardiology, urology, neonatology, and even toxicology. Table 1 summarizes the demographic characteristics of the participants. General pediatricians were more likely to be female (57\%) than subspecialists $(40 \%)$ and more likely to work in the outpatient setting $(73 \%$ versus $21 \%$ ).

Table 1. Characteristics of physicians responding.

\begin{tabular}{|c|c|c|c|c|}
\hline & General Pediatrician $(n=431)$ & Pediatric Specialist $(\mathrm{n}=151)$ & Chi square $^{\mathrm{a}}$ & $P$ value \\
\hline Gender (female) & $57 \%$ & $40 \%$ & 14.06 & 0.00 \\
\hline \multicolumn{5}{|l|}{ Region: } \\
\hline Northeast & $25 \%$ & $18 \%$ & \multirow{4}{*}{9.40} & \multirow{4}{*}{0.02} \\
\hline Southeast & $37 \%$ & $33 \%$ & & \\
\hline Midwest & $17 \%$ & $28 \%$ & & \\
\hline West & $21 \%$ & $21 \%$ & & \\
\hline \multicolumn{5}{|l|}{ Type of activity: } \\
\hline Outpatient & $73 \%$ & $21 \%$ & \multirow{5}{*}{147.57} & \multirow{5}{*}{0.00} \\
\hline Hospital & $15 \%$ & $45 \%$ & & \\
\hline Government & $2 \%$ & $3 \%$ & & \\
\hline Medical School & $6 \%$ & $28 \%$ & & \\
\hline Other & $5 \%$ & $3 \%$ & & \\
\hline \multicolumn{5}{|c|}{ Year of medical school completion: } \\
\hline After 2004 & $17 \%$ & $6 \%$ & \multirow{7}{*}{23.97} & \multirow{7}{*}{0.00} \\
\hline $2000-2003$ & $13 \%$ & $14 \%$ & & \\
\hline 1990-1999 & $32 \%$ & $27 \%$ & & \\
\hline $1980-1989$ & $20 \%$ & $25 \%$ & & \\
\hline $1970-1979$ & $11 \%$ & $20 \%$ & & \\
\hline 1960-1969 & $4 \%$ & $8 \%$ & & \\
\hline Before 1960 & $2 \%$ & $0 \%$ & & \\
\hline Has children & $78 \%$ & $85 \%$ & 2.82 & 0.09 \\
\hline
\end{tabular}

${ }^{\mathrm{a}}$ Using two-way tables with measures of association. 
Overall, out of 466 respondents who reported having children, 438 (94\%) stated that they followed ACIP recommendations regarding vaccination. This rate was slightly higher among general pediatricians ( $95 \%$ vs $93 \%)$ but the difference was not statistically significant. Overall rates for individual vaccines were considerably high ranging from $97 \%$ to $100 \%$ for both general pediatricians and specialists (Table 2). The lower rate of overall compliance with the ACIP recommendations is likely accounted for by differences among which vaccines physicians elected to skip for their children. One notable trend, however, was that physicians who graduated from medical school prior to 1990 were less likely to vaccinate their own children for rotavirus (OR: 10; 95\% CI: 1.1 $81 \mathrm{P}$ value 0.038 ).

When asked about how they would vaccinate a potential child in 2009, larger differences emerged between general pediatricians and specialists (Table 3). Respondents included both those who have and do not have children $(\mathrm{n}=554)$. Specialists were found to be less likely to follow the overall schedule. 41 generalists $(9.9 \%)$ and 29 specialists (21\%) reported they would skip at least one vaccine for their future child (Chi square = 0.001). Specifically, generalists in 2009 were more likely

Table 2. Reported vaccination practices of respondents who have their own children.

\begin{tabular}{|c|c|c|c|c|c|}
\hline & Generalist $(n=336)$ & Subspecialist $(\mathrm{n}=128)$ & $P$ value & Adjusted $\mathrm{OR}^{\mathrm{a}}$ & $95 \% \mathrm{CI}^{\mathrm{b}}$ \\
\hline Followed ACIP recommendation & $95 \%$ & $92 \%$ & 0.39 & 0.7 & $0.3-1.7$ \\
\hline $\mathrm{DTaP}$ & $100 \%$ & $100 \%$ & & & \\
\hline Hib & $100 \%$ & $100 \%$ & & & \\
\hline Pneumococcal & $100 \%$ & $99 \%$ & 0.79 & 1.5 & $0.1-27.9$ \\
\hline IPV & $100 \%$ & $99 \%$ & 0.88 & 1.3 & $0.1-25.9$ \\
\hline Rotavirus & $98 \%$ & $98 \%$ & 0.60 & 0.6 & $0.1-3.4$ \\
\hline Hepatitis A & $99 \%$ & $98 \%$ & 0.64 & 1.4 & $0.3-6.9$ \\
\hline Hepatitis B & $99 \%$ & $99 \%$ & 0.55 & 0.5 & $0-5.5$ \\
\hline MMR & $98 \%$ & $100 \%$ & & & \\
\hline Varicella & $99 \%$ & $97 \%$ & 0.39 & 1.9 & $0.4-8.8$ \\
\hline Meningococcal & $100 \%$ & $98 \%$ & & & \\
\hline Influenza & $99 \%$ & $99 \%$ & 0.51 & 0.5 & $0-4.8$ \\
\hline
\end{tabular}

${ }^{a}$ Using binomial regression model, controlling for the following independent variables: speciality (generalist vs specialist), gender, graduation year (after 1990 or before), living in western states (yes, no), practicing in hospital (yes, no). ${ }^{\mathrm{b}} \mathrm{OR}$ and $\mathrm{CI}$ not calculated if the $\%$ of one of the outcomes of the dependent variable was $\leq 1 \%$.

Table 3. Projected pattern of vaccination of all respondents.

\begin{tabular}{|c|c|c|c|c|c|}
\hline & Generalist $(n=416)$ & Subspecialist $(\mathrm{n}=138)$ & $P$ value & Adjusted $\mathrm{OR}^{\mathrm{a}}$ & $95 \% \mathrm{CI}^{\mathrm{b}}$ \\
\hline Would postpone MMR until after 18 months & $5 \%$ & $19 \%$ & 0.00 & 4.4 & $2.3-8.6$ \\
\hline Would not give $\mathrm{DTaP}$ & $0.5 \%$ & $0 \%$ & & & \\
\hline Would not give Hib & $0 \%$ & $0 \%$ & & & \\
\hline Would not give Prevnar & $0.7 \%$ & $0 \%$ & & & \\
\hline Would not give IPV & $0.2 \%$ & $0 \%$ & & & \\
\hline Would not give Rotavirus & $6 \%$ & $12 \%$ & 0.03 & 2.2 & $1.1-4.4$ \\
\hline Would not give Hepatitis A & $2 \%$ & $6 \%$ & 0.02 & 3.6 & $1.3-10.4$ \\
\hline Would not give Hepatitis B & $0.2 \%$ & $1 \%$ & 0.83 & 1.4 & $0.1-28.4$ \\
\hline Would not give MMR & $1 \%$ & $1 \%$ & 0.83 & 0.8 & $0.1-8.7$ \\
\hline Would not give Varicella & $1 \%$ & $2 \%$ & 0.30 & 2.3 & $0.5-11.6$ \\
\hline Would not give Menactra & $1 \%$ & $9 \%$ & 0.00 & 9.9 & $3.3-29.9$ \\
\hline Would not give Influenza & $1 \%$ & $3 \%$ & 0.04 & 5.4 & $1.1-26.7$ \\
\hline Would not give Gardasil & $1 \%$ & $1 \%$ & 0.57 & 0.5 & $0.1-4.8$ \\
\hline
\end{tabular}

${ }^{\mathrm{a}}$ Using binomial regression model, controlling for the following independent variables: speciality (generalist vs specialist), gender, graduation year (after 1990 or before), living in western states (yes, no), practicing in hospital (yes, no). ${ }^{\mathrm{b}} \mathrm{OR}$ and CI not calculated if the \% of one of the outcomes of the dependent variable was $\leq 1 \%$. 
to give a future child Hepatitis A (OR: 3.6; 95\% CI 1.3 10.4), Rotavirus (OR: 2.2; 95\% CI 1.1 - 4.4), Meningococcal (OR: 9.9; 95\% CI 3.3 - 29.9), and Influenza (OR: $5.4 ; 95 \%$ CI 1.1 - 26.7) vaccines. Pediatric specialists reported a stronger desire to postpone future MMR vaccination (OR: 4.4 95\% CI $2.3-8.6$ ), but even 5\% of general pediatricians reported they also would postpone this vaccine beyond 18 months. Of the respondents who would elect to withhold at least one vaccine for future progeny (63 of 70 who actually reported having children), the most common reason given was "safety" and "too many vaccines given at once" (Table 4). This pattern was also seen for those respondents who have children and elected not to receive vaccines as recommended by the ACIP (Table 5). Place of work such as in "private practice" or "for the government" did not demonstrate to play a role in choosing to vaccinate in either specialists or generalists.

Table 4. Physicians' reasons for withholding immunization of future progeny.

\begin{tabular}{lcc}
\hline & Generalist $(\mathrm{n}=41)$ & Subspecialist $(\mathrm{n}=29)$ \\
\hline Medical contraindication & $1(2.4 \%)$ & $3(3.4 \%)$ \\
Too many vaccines given at once & $4(9.8 \%)$ & $10.3 \%)$ \\
Safety concern & $12(29.3 \%)$ & $12(41.4 \%)$ \\
Do not believe in efficacy of vaccine & $3(7.3 \%)$ & $2(6.9 \%)$
\end{tabular}

"In developed countries Rotavirus is for the most part treatable and I've seen some side effects."

"Rotavirus is negligible in US. More of a problem in 3rd world but vaccine ineffective there."

"Very low incidence; vaccination not warranted (Hep A)."

“(Gardasil) is not appropriate for USA population, doesn't remove need for exams, better served in other parts of world."

"Not important (Gardasil) to my daughter and presumes promiscuity."

"Not convinced of need (Hep A)."

“1) A newborn does not need Hep B, 2) Hep A is rare in US, and 3) Rotavirus is too new."

Other
"Would not bundle vaccines."
"New to the market, awaiting long term research (Gardasil)."
"Children got H1N1 and protected from disease." science but good art. (regarding delay of MMR)."
"Feel HAV us unnecessary at that age."
"Risk is greater than negligible benefit in my family situation (rotavirus)."
"Severity of illness does not warrant vaccination (rotavirus)."

"No need to introduce another potentially confounding variable until development is clearly normal. Poor

Table 5. Physicians' reasons for withholding immunization of their own children (those who actually have children).

\begin{tabular}{lcc}
\hline & Generalist $(\mathrm{n}=15)$ & Subspecialist (n=9) \\
\hline Medical contraindication & $1(6.7 \%)$ & 0 \\
Too many vaccines given at once & $3(20 \%)$ & $3(33 \%)$ \\
Safety concern & $2(20 \%)$ & $1(33 \%)$ \\
Do not believe in efficacy of vaccine & $2(13 \%)$ & $(11 \%)$ \\
& "Wanted to see if [child] got chickenpox and ensure lifetime immunity." & \\
& "Knew baby at low risk [for hepatitis B] at birth, decided to start series at 2 mos checkup." \\
& "Not in school,limited exposure,able to space them out." & \\
& "Risk exceeds benefit in my family (stay at home parent)." & "Illness itself is usually not severe enough to warrant vaccination (i.e., rotavirus)." \\
& "One child on chemo; other was PDD; other two got everything on schedule."
\end{tabular}




\section{DISCUSSION}

Until now few studies have examined how pediatricians in the US vaccinate their own children [6,7]. The results of this study bridge this gap by confirming that a high percentage, $94 \%$ of respondents, vaccinated their own children according to ACIP recommendations through 2009 and will likely continue to do so in the future. This important message of "lead by example" should be communicated to a public who is increasingly concerned over the need and safety of vaccines. For those charged with vaccinating and caring for children, there is a strong uniformity with respect to their own children in the actual practice of immunizing as per ACIP recommendations. One of the most common questions asked to pediatricians is "what would you do with your child?" This study answers this question.

Pediatric specialists and general pediatricians do appear potentially poised to diverge further from ACIP recommendations with future progeny. This trend was much larger in the subspecialist group. This may be due to the greater ignorance of subspecialists with regards to the vaccines and the diseases they prevent. Future studies might look to correlate the specialty with electing not to give certain vaccines. Those physicians responding they would not follow recommendations cited safety as their largest concern. This parallels the trend of increasing safety concerns by parents [13-15]. Reasons for safety concerns given by physicians ranged from claims of vaccines being "too new," of perceived "risk" being "greater than [the] negligible benefit," and even a perceived "risk" in bundling vaccines (Tables 4 and 5).

A significant number of subspecialists did not want to give hepatitis A (6\%), rotavirus (12\%), and meningococcal vaccine $(9 \%)$ moving forward. Comments of those who would not give hepatitis A included "[I am] not convinced of the need", "[I] feel Hepatitis A vaccinetion is unnecessary at that age", "severity of [the] illness does not warrant vaccination", and the "risk exceeds the benefit in my family (stay at home parent)". Despite evidence of the enormous cost savings and reduction in rotavirus morbidity and incidence in the United States, many physicians in the study appeared to feel that rotavirus vaccination at the individual level was not appropriate in their future progeny $[16,17]$. It may be that those physicians who practiced in 1999 are biased against the rotavirus vaccine having witnessed the recall of the rotavirus vaccine, Rotashield, due to an association with intussusception. Older physicians, those graduating prior to 1990, in our study demonstrated to be less inclined to vaccinate with rotavirus compared to their younger counterparts. With meningococcal vaccine, safety again was observed to be the major barrier that needs to be addressed with pediatric specialists. The most significant differential between projected immunizations of children of general pediatricians versus specialists was with meningococcal vaccination. This possibly reflects the greater exposure of general pediatricians with the serious outcomes of the disease caused by this organism.

What is observed from this study is the intent of some general pediatricians $(5 \%)$ and a higher proportion of specialists $(19 \%)$ to delay the MMR vaccination beyond 18 months of age despite recent increases in incidence of Measles disease [18]. This is somewhat unexpected given the time and resources spent to discredit any association between MMR and autism, but it does mimic the public trend. One physician even goes so far to comment that there is "no need to introduce another potentially confounding variable (MMR vaccine) until development is clearly normal." This potential trend represents a major threat to effectively combating the current rise in measles. Such physicians may not feel compelled to argue for timely vaccination with MMR.

Electing not to vaccinate leads to poor outcomes for many. In a retrospective cohort study spanning 10 years, unvaccinated children were found to be 22 times more likely to contract measles and 6 times more likely to contract pertussis than vaccinated children [19]. In 2008, the most measles cases since 1996 occurred. 112 of a total of 131 cases were unvaccinated or had unknown vaccination status [20]. In 2009, approximately $0.6 \%$ of children between 19 and 35 months received no vaccinations and represents an increase from $0.4 \%$ from 2006 [18]. Despite these trends, delaying MMR vaccination based on our findings may increase among pediatric clinicians.

Our results did show some methodological limitations necessitating caution in interpreting them. Recollection bias may have influenced answers that relied on physicians' recall of past vaccine practices. Also, answers for a hypothetical child, may not necessarily translate into actions once a physician has an actual child. This survey drew from a pool of pediatric providers who were far more likely to be interested in vaccine issues as immunization of all children is a primary stated goal of the AAP. This suggests that compliance of the survey respondents in vaccinating their own children according to ACIP guidelines will be higher than for the general population of pediatric providers in the US. The survey also did not address whether responders were actively charged with vaccinating patients. It is not known whether those working "for the government" or "in a school of medicine" actually vaccinate children in their workplace. It is also possible that questionnaires were sent to pediatricians who were parents of the same child although no physicians bearing the same last name who completed the questionnaire were located in the same state. Unfortunately, from the database it was not possible to elicit relationships of physicians surveyed. 
While most pediatricians and pediatric specialists (95\% and 93\%) have adhered to the recommended ACIP vaccination schedule up until 2009, a potential for change emerged with $10 \%$ of pediatricians and $21 \%$ of pediatric specialists claiming they would not follow the recommendations for future progeny. Despite their education, physicians in this study expressed concern over the safety of vaccines. This study points to the need to focus on education efforts, including safety data, for those particular vaccines physicians displayed the greatest concern over including hepatitis A, rotavirus, meningococcal, and measles. Pediatric specialists should be included in this education as they have the greatest concerns, may be the most removed from the diseases protected by the immunizations, but also care for some of the most vulnerable populations. It has been shown that the more convinced physicians are of the benefits of vaccines, the more likely they are to immunize their patients [21-23].

Researchers might look to correlate whether patients of physicians who choose not to follow current recommendations are indeed more likely to also not follow the published schedule. Continued control of communicable disease will rely on the success of efforts to educate the public and physicians. Future study should thus focus on how to best address safety concerns which presents the greatest threat to sustained high vaccination level.

\section{ACKNOWLEDGEMENTS}

An educational grant for this study was provided by Inova Health Systems.

\section{REFERENCES}

[1] Smith, P.J., Kennedy, A.M., Wooten, K., Gust, D.A. and Pickering, L.K. (2006) Association between health care providers' influence on parents who have concerns about vaccine safety and vaccination coverage. Pediatrics, 118, e1287-e1292. doi:10.1542/peds.2006-0923

[2] Benin, A.L., Wisler-Scher, D.J., Colson, E., Shapiro, E.D. and Holmboe, E.S. (2006) Qualitative analysis of mothers' decision-making about vaccines for infants: The importance of trust. Pediatrics, 117, 1532-1541. doi:10.1542/peds.2005-1728

[3] Sharkness, C.M., Goun, B.D., Davis, L.A. and Sykes, L.E. (1998) Do we practice what we teach about childhood immunization in New Jersey? Family Medicine, 30, 727732.

[4] Zimmerman, R.K., Bradford, B.J., Janosky, J.E., Mieczkowski, T.A., DeSensi, E. and Grufferman, S. (1997) Barriers to measles and pertussis immunization: The knowledge and attitudes of Pennsylvania primary care physiccians. American Journal of Preventative Medicine, 13, 89-97.

[5] Gust, D.A., Strine, T.W., Maurice, E., Smith, P., et al.
(2004) Underimmunization among children: Effects of vaccine safety concerns on immunization status. Pediatrics, 2004, 114, e16-e22. doi:10.1542/peds.114.1.e16

[6] Katz-Sidlow, R.J. and Sidlow, R. (2003) A look at the pediatrician as parent: Experiences with the introduction of varicella vaccine. Clinical Pediatrics, 28, 635-640. doi: $10.1177 / 000992280304200710$

[7] Posfay-Barbe, K.M., Heininger, U., Aebi, C., Desgrandchamps, D., Vaudaux, B. and Siegrist, C.A. (2005) How do physicians immunize their own children? Differences among pediatricians and nonpediatricians. Pediatrics, 116, e623-e633. doi:10.1542/peds.2005-0885

[8] Kempe, A., Patel, M.M., Daley, M.F., Crane, L.A., Beaty, B., Stokley, S., Barrow, J., Babbel, C., Dickinson, L.M., Tempte, J.L. and Parashar, U.D. (2009) Adoption of rotavirus vaccination by pediatricians and family medicine physicians in the United States. Pediatrics, 124, e809e816. doi:10.1542/peds.2008-3832

[9] Davis, M.M., Marin, M., Cowan, A.E., Guris, D. and Clark, S.J. (2007) Physician attitudes regarding breakthrough varicella disease and a potential second dose of varicella vaccine. Pediatrics, 119, 258-264. doi:10.1542/peds.2006-0972

[10] Freed, G.L., Bordley, W.C., Clark, S.J. and Konrad, T.R. (1993) Reactions of pediatricians to a new Centers for Disease Control recommendation for universal immunization of infants with hepatitis B vaccine. Pediatrics, 91, 699-702.

[11] Davis, M.M., Ndiaye, S.M., Freed, G.L., Kim, C.S. and Clark, S.J. (2003) Influence of insurance status and vaccine cost on physicians' administration of pneumococcal conjugate vaccine. Pediatrics, 112, 521-526. doi:10.1542/peds.112.3.521

[12] Gust, D., Weber, D., Weintraub, E., Kennedy, A., Sund, F. and Burns, A. (2008) Physicians who do and do not recommend children get all vaccinations. Journal of Health Communication: International Perspectives, 13, 573-582. doi:10.1080/10810730802281726

[13] Gellin, B.G., Maibach, E.W. and Marcuse, E.K. (2000) Do parents understand immunizations? A national telephone survey. Pediatrics, 106, 1097-1102. doi:10.1542/peds.106.5.1097

[14] Gust, D.A., Darling, N., Kennedy, A. and Schwartz, B. (2008) Parents with doubts about vaccines: Which vaccines and reasons why. Pediatrics, 122, 718-725. doi:10.1542/peds.2007-0538

[15] Freed, G.L., Clark, S.J., Butchart, A.T., Singer, D.C. and Davis, M.M. (2010) Parental vaccine safety concerns in 2009. Pediatrics, 125, 654-659. doi:10.1542/peds.2009-1962

[16] Widdowson, M.-A., Meltzer, M.I., Zhang, X.Z., Bresee, J.S., Parashar, U.D. and Glass, R.I. (2007) Cost-effectiveness and potential impact of rotavirus vaccination in the United States. Pediatrics, 119, 684-697. doi:10.1542/peds.2006-2876

[17] Anderson, E.J., Rupp, A., Shulman, S.T., Wang, D.L., Zheng, X.T. and Noskin, G.A. (2011) Impact of rotavirus vaccination on hospital-acquired rotavirus gastroenteritis in children. Pediatrics, 127, e264-e270. 
doi:10.1542/peds.2010-1830

[18] Centers for Disease Control and Prevention (2010) National, state, and local area vaccination coverage levels among children aged 19-35 months_-United States, 2009. Morbidity and Mortality Weekly Report (MMWR), 59, 1171-1177.

[19] Feiken, D.R., Lezott, D.C., Hamman, R.F., Soloman, D.A., Chen, R.T. and Hoffman, R.E. (2000) Individual and community risks of measles and pertussis associated with personal exemptions to immunization. The Journal of the American Medical Association, 284, 3145-3150. doi:10.1001/jama.284.24.3145

[20] Centers for Disease Control and Prevention (2008) Update: Measles-United States, January-July 2008. Morbidity and Mortality Weekly Report (MMWR), 57, 893-
896.

[21] Iwamoto, M., Saari, T.N., McMahon, S.R., et al. (2003) A survey of pediatricians on the reintroduction of a rotavirus vaccine. Pediatrics, 112, e6-e10. doi:10.1542/peds.112.1.e6

[22] Zimmerman, R.K., Schlesselman, J.J., Baird, A.L. and Mieczkowski, T.A. (1997) A national survey to understand why physicians defer childhood immunizations. Archives of Pediatrics Adolescent Medicine, 151, 657-664. doi:10.1001/archpedi.1997.02170440019004

[23] Zucs, A.P., Crispin, A., Eckl, E., Weitkkunat, R. and Schlipkoter, U. (2004) Risk factors for undervaccination against measles in a large sample of preschool children from rural Bavaria. Infection, 32, 127-133. doi:10.1007/s15010-004-3122-0 